\title{
AMERICAN WHITE PELICANS FEEDING ON LARGE FISH IN LANIGAN CREEK, SASKATCHEWAN
}

American white pelicans (Pelecanus erythrorhynchos) are a common sight on Saskatchewan lakes and rivers, where they forage for fish and amphibians. Pelicans are buoyant birds that sit on the water and dip their large bills below the surface to capture aquatic prey. The majority of pelican diet on the northern Great Plains is comprised of small fish, crayfish, and salamanders that they catch in shallow, near-shore areas. ${ }^{1}$ An alternate foraging strategy used fairly often by pelicans in Saskatchewan is to wait below water control structures in rivers and creeks; here they target fish that gather as a result of impeded passage, or that are disoriented as they pass over or through the structure. Some 'hot-spots' for viewing this pelican foraging behaviour include the downstream side of the weir in the South Saskatchewan River in the city of Saskatoon, the Finlay and Campbell dams flanking Tobin Lake, and the Gardiner dam on Lake Diefenbaker. A lesser known location, but a spectacular one for close viewing of pelicans, is below the control structure on Lanigan Creek in the Last Mountain Lake National Wildlife Area and Migratory Bird Sanctuary (Fig. 1A). Up to several hundred pelicans may be present in the small pool below the control structure at any given time, depending on conditions (Fig. 1B).

In May of 2005 we spent 19 hours over a number of days observing pelicans foraging downstream of the Lanigan Creek control structure as part of a larger study on the diet of fish-eating birds in Saskatchewan. We used the length of fish captured relative to the length of pelican bills to estimate the size of fish caught
(Fig. 2), and external features of the fish viewed with binoculars to identify species when possible.

During our observations, pelicans appeared to be targeting almost exclusively large fish when foraging below the Lanigan Creek control structure. Of 77 individual fish captured, all were 30 to $50 \mathrm{~cm}$ in length. We were able to clearly see identifying features of 19/77 ( 25\%) fish, which were of the following species: $14(74 \%)$ common carp (Cyprinus carpio), $3(16 \%)$ white sucker (Catostomus commersonii), and $2(11 \%)$ northern pike (Esox lucius). Thus, pelicans in Lanigan Creek seem to be consuming mainly non-native carp. However, we are uncertain how well our data set reflects the actual diet of pelicans at this location because most of the fish captured (58 of 77 individuals) were not identified. The large fish captured were challenging for pelicans to handle, and they often fought extensively to steal prey from other birds (Fig. 3). There is good reason for the competition; a 50-cm carp would weigh approximately $1800 \mathrm{~g}$, which represents the complete daily intake requirement for a pelican in one prey item.

1. Knopf FL, Evans RM (2004) American White Pelican (Pelecanus erythrorhynchos). In: Poole A (ed) The Birds of North America Online. Cornell Lab of Ornithology, Ithaca, NY; Retrieved from the Birds of North America Online: http://bna.birds.cornell. edu/bna/species/057doi:10.2173/bna. 57

- Christopher M. Somers, ${ }^{1}$ Victoria A. Kjoss, ${ }^{1}$ Department of Biology, University of Regina, Regina, SK; E-mail: <chris. somers@uregina.ca> 

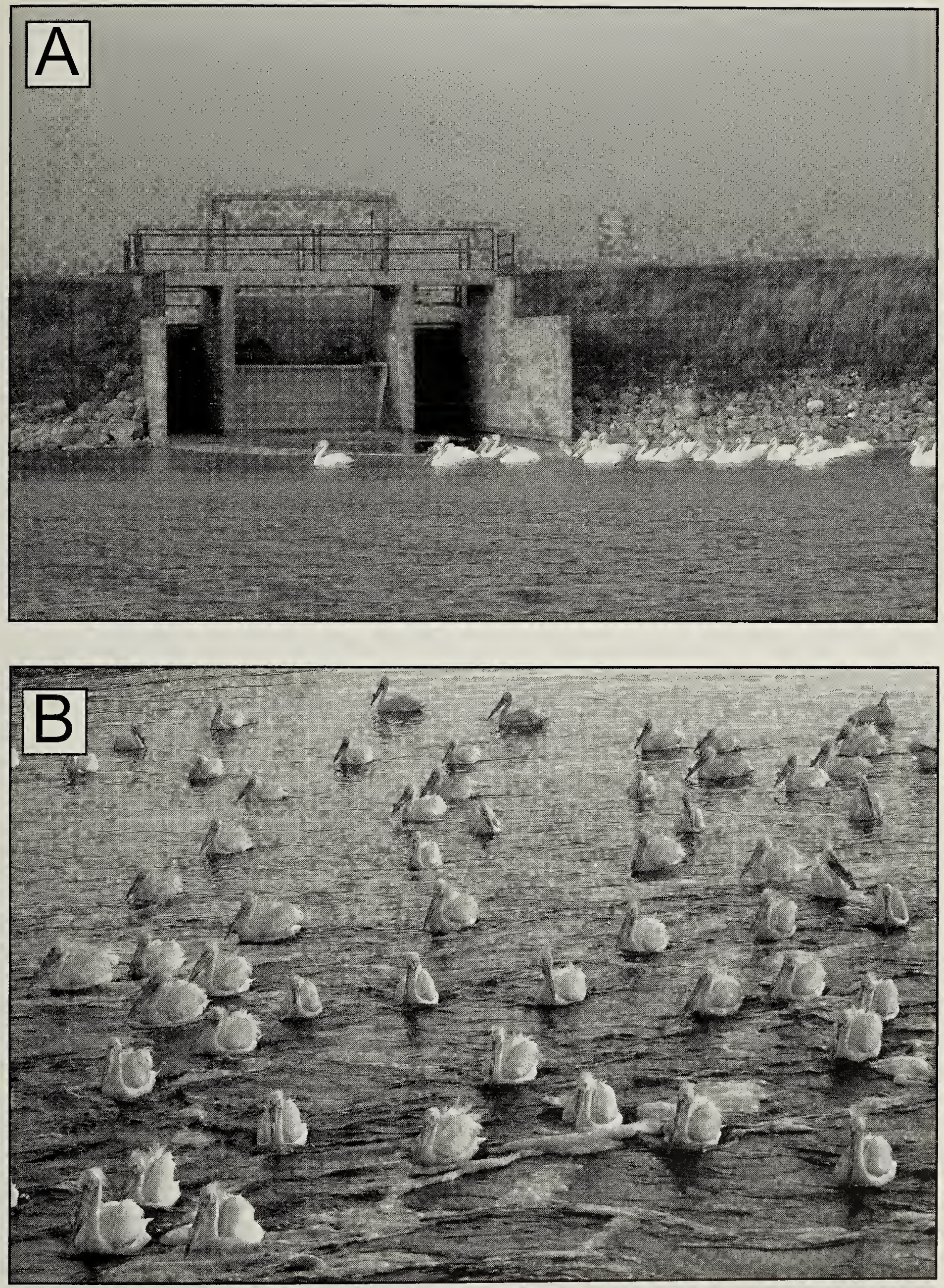

Figure 1. (A) Pelicans below the water control structure in Lanigan Creek on the Last Mountain Lake National Wildlife Area and Migratory Bird Sanctuary. (B) A group of pelicans searching for fish in Lanigan Creek.

Christopher Somers 


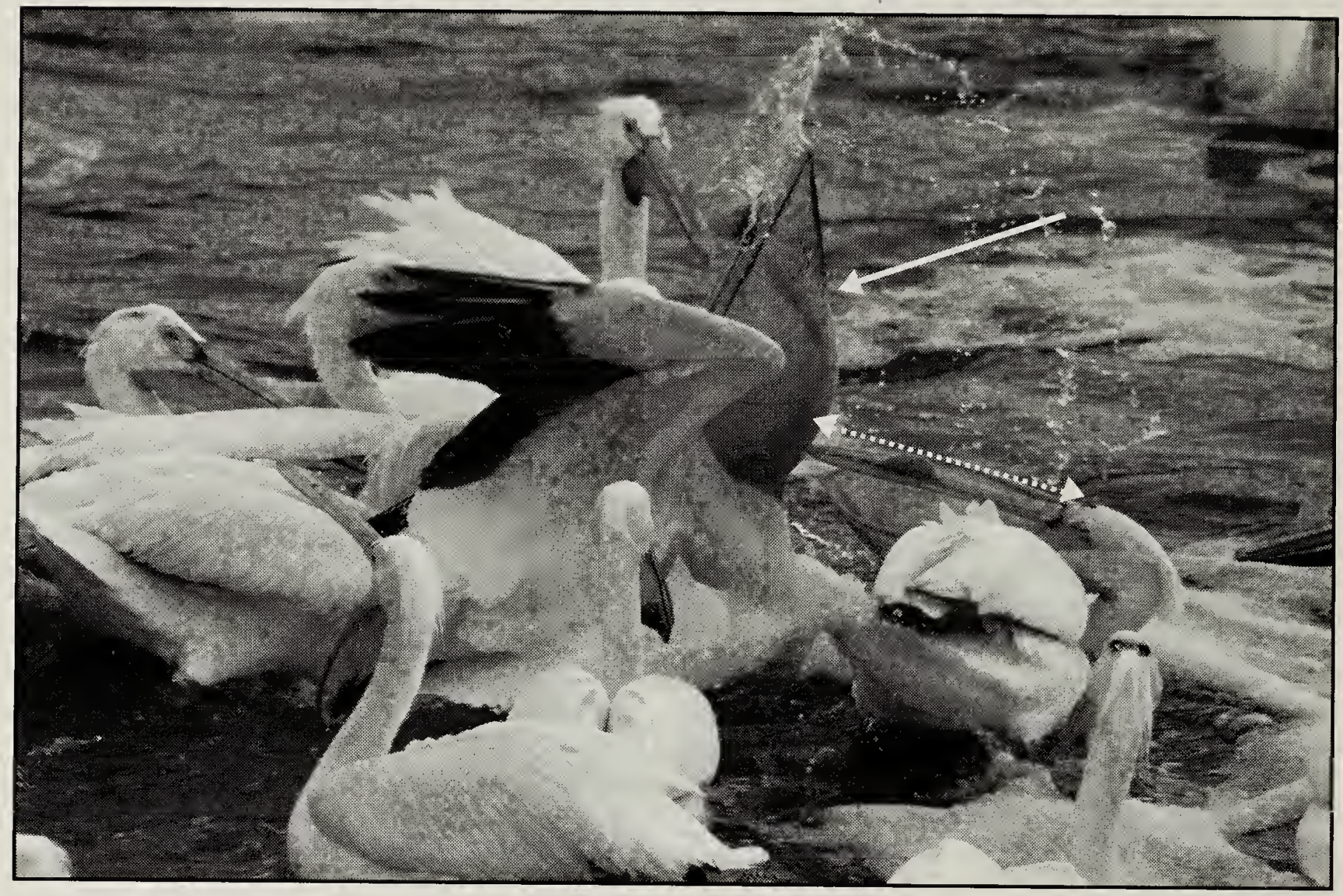

Figure 2. American white pelican capturing a large fish (solid arrow) in Lanigan Creek, Saskatchewan. The bill length for most pelicans is approximately $30 \mathrm{~cm}$ (dashed arrow); the fish captured here is curved along its body length, but is actually longer than the bill of the bird catching it.

Christopher Somers

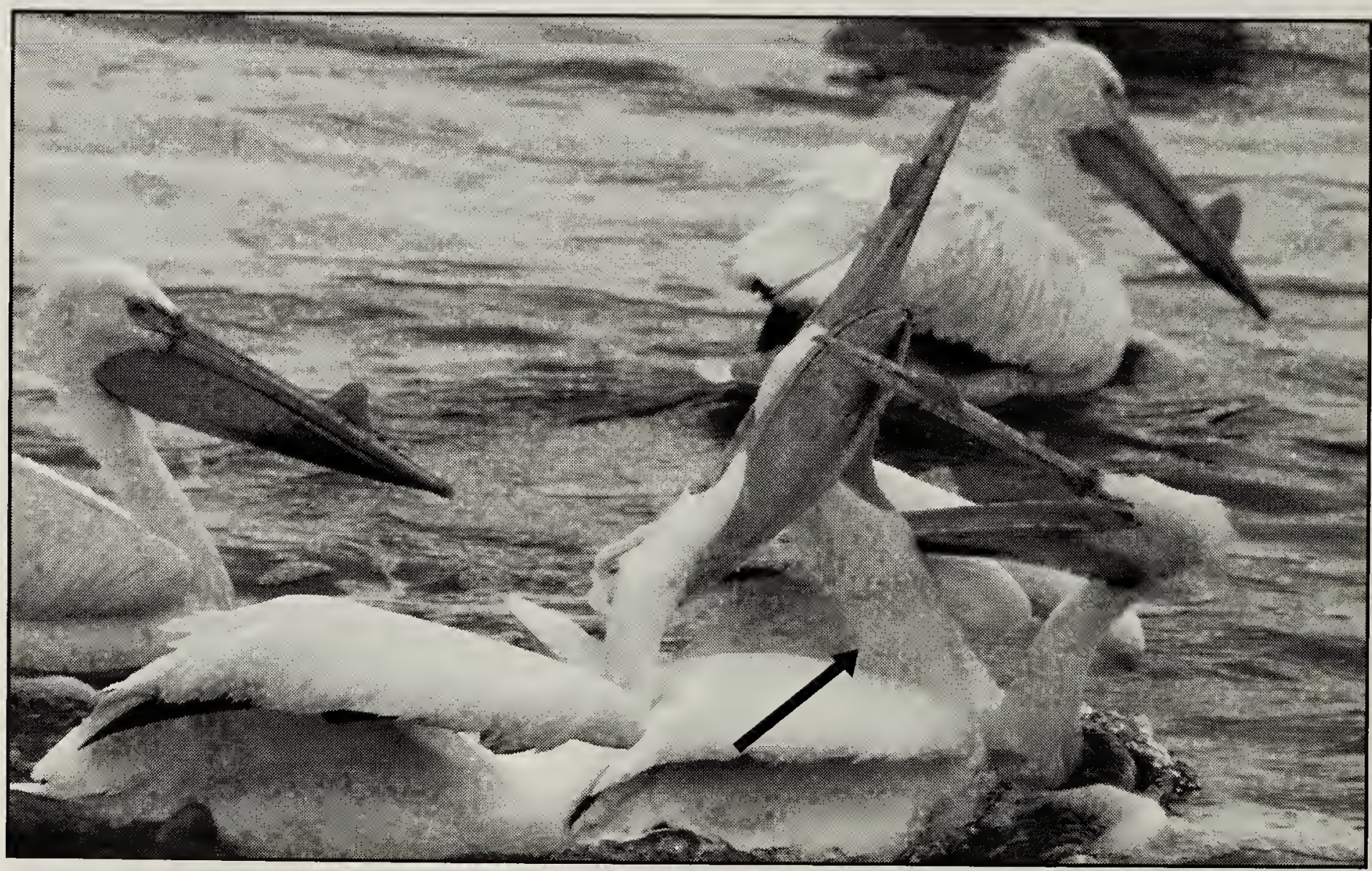

Figure 3. Pelicans fight over a large fish captured in Lanigan Creek. The bird in the center has already swallowed the fish, which is causing the throat distension that is visible (arrow). Christopher Somers 